\title{
SMR
}

$\underline{\text { Short Communication }}$

\section{Development of microsatellite markers and genetic diversity analysis for Pelodiscus sinensis}

T. Li ${ }^{1,2}$, J. Zhao ${ }^{1}$, W. Li ${ }^{1}$, Y. Shi ${ }^{1}$, X.Y. Hong ${ }^{1,2}$ and X.P. Zhu ${ }^{1,2}$

${ }^{1}$ Key Laboratory of Tropical and Subtropical Fishery Resource Application and Cultivation of Ministry of Agriculture,

Pearl River Fisheries Research Institute, Chinese Academy of Fishery Sciences, Guangzhou, China

${ }^{2}$ College of Life Science and Technology, Shanghai Ocean University, Shanghai, China

Corresponding author: X.P. Zhu

E-mail: zhuxinping_1964@163.com

Genet. Mol. Res. 15 (3): gmr.15038346

Received December 28, 2015

Accepted February 26, 2016

Published July 29, 2016

DOI http://dx.doi.org/10.4238/gmr.15038346

Copyright (C) 2016 The Authors. This is an open-access article distributed under the terms of the Creative Commons Attribution ShareAlike (CC BY-SA) 4.0 License.

ABSTRACT. Pelodiscus sinensis is a common freshwater soft-shell turtle found in China, and is an important aquaculture species. In this study, 20 polymorphic microsatellite primers were developed from the transcriptome. The genetic diversity of three populations of $P$. sinensis was evaluated, using 72 individuals. The number of alleles per locus ranged from 3 to 26. The observed and expected heterozygosities varied from 0.208 to 0.958 , and from 0.302 to 0.963 , respectively. The polymorphic information content varied from 0.283 to 0.953 . No significant linkage 
disequilibrium was detected. These markers will be useful for future population genetic studies and molecular breeding of $P$. sinensis.

Key words: Pelodiscus sinensis; Chinese soft-shell turtle; Microsatellites; Genetic diversity

\section{INTRODUCTION}

The Chinese soft-shell turtle, Pelodiscus sinensis, is a common and widely distributed freshwater turtle in China. It is an important aquaculture species, and the annual output reached 340,000 tons in 2014 (Bureau of Fisheries, Ministry of Agriculture, China, 2015). It is also distributed in Japan, Korea, Vietnam, and in other Southeast Asian countries (Fritz et al., 2010). Because of its wide distribution, there are many different geographical populations of $P$. sinensis, and each population has distinctive genetic characteristics. Microsatellite markers are valuable tools for use in genetic studies and for genetic resources conservation and management (Bai et al., 2011; Lin et al., 2012). In this study, 20 novel microsatellite markers were developed and used to analyze the population genetics of three geographical populations of Chinese soft-shell turtle. These markers will be useful for population genetic studies and molecular breeding of $P$. sinensis.

\section{MATERIAL AND METHODS}

Three geographical populations of Chinese soft-shell turtle, including 72 individuals, were sampled. Twenty-four individuals were collected from the Yangtze River system (YR), 24 from the Pearl River system (PR), and 24 from Japan (JAP). Genomic DNA was extracted from the nails using Omega Micro Elute Tissue DNA Kit according to manufacturer protocol.

A total of 100 pairs of candidate microsatellite primers were designed and developed from the transcriptome of the Chinese soft-shell turtle. A M13 tail was added to the 5' end of each forward primer (5'-CACGACGTTGTAAAACGAC-3') (Table 1).

Polymerase chain reaction (PCR) was performed in a $10-\mu \mathrm{L}$ volume containing $5 \mu \mathrm{L}$ AB Multiplex PCR Master Mix, $2 \mu \mathrm{L}$ primer mixture with the appropriate primer ratio (forward primer: reverse primer in 1:40 ratio), $0.2 \mu \mathrm{L}$ fluorescence labeled M13-forward primer, $1 \mu \mathrm{L}$ $20 \mathrm{ng} / \mu \mathrm{L}$ DNA, and $1.8 \mu \mathrm{L}$ deionized water. Amplifications were carried out in an Eppendorf master cycler using the following procedure: initial denaturation at $94^{\circ} \mathrm{C}$ for $5 \mathrm{~min}$, followed by 22 cycles of $30 \mathrm{~s}$ at $94^{\circ} \mathrm{C}, 30 \mathrm{~s}$ at the annealing temperature of $55^{\circ}-63^{\circ} \mathrm{C}$ (Table 1 ), and $40 \mathrm{~s}$ at $72^{\circ} \mathrm{C}$, then eight cycles of $30 \mathrm{~s}$ at $94^{\circ} \mathrm{C}, 30 \mathrm{~s}$ at the annealing temperature of $53^{\circ} \mathrm{C}$, and $50 \mathrm{~s}$ at $72^{\circ} \mathrm{C}$. A final elongation of $10 \mathrm{~min}$ at $72^{\circ} \mathrm{C}$ was added, holding at $4^{\circ} \mathrm{C}$. A sample of $2 \mu \mathrm{L}$ of the PCR products was mixed with $9 \mu \mathrm{L}$ Hi-Di containing Genescan 500Liz (Applied Biosystems Grange, Woolston, Warrington, UK), denatured for $5 \mathrm{~min}$ at $94^{\circ} \mathrm{C}$, and chilled immediately on an ice plate. The mixture was separated using an ABI genetic analyzer 3130.

The alleles were detected by the Peak scanner software V1.0 (downloaded from http:// www. Lifetechnologies.com). Pop gene 32 (Yeh et al., 2000) and Cervus 3.0 (Kalinowski et al., 2007) softwares were used to assess the genetic parameters of the 20 markers, including the number of alleles, observed $\left(H_{\mathrm{O}}\right)$ and expected heterozygosities $\left(H_{\mathrm{E}}\right)$, polymorphism information content, and the departure from the Hardy-Weinberg equilibrium. MEGA5.0 was used to establish the relationships between the three Chinese soft-shelled turtle populations.

Genetics and Molecular Research 15 (3): gmr.15038346 
Table 1. Characteristics of the 20 novel microsatellite loci identified in this study.

\begin{tabular}{|c|c|c|c|c|}
\hline Locus & Primer sequence & Repeat motif & Size range $(b p)$ & $\mathrm{Ta}\left({ }^{\circ} \mathrm{C}\right)$ \\
\hline \multirow[t]{2}{*}{ ZYF1 } & F-GTGGGTGTTTGGTCAAGGAT & \multirow[t]{2}{*}{ (TG)6 } & \multirow[t]{2}{*}{$86-125$} & \multirow[t]{2}{*}{63} \\
\hline & R-CTTCCACACACACAACCCTG & & & \\
\hline \multirow[t]{2}{*}{ ZYH18 } & F-CAGACCCAACAACCCAATCT & \multirow[t]{2}{*}{$(\mathrm{ATAG}) 5$} & \multirow[t]{2}{*}{$253-293$} & \multirow[t]{2}{*}{63} \\
\hline & R-TGAAAGCACACCACCCAGTA & & & \\
\hline \multirow[t]{2}{*}{ ZYH30 } & F-AGAAGAGAGGGGGTGAGAGC & \multirow[t]{2}{*}{$(\mathrm{GACA}) 4$} & \multirow[t]{2}{*}{$273-302$} & \multirow[t]{2}{*}{63} \\
\hline & R-GCGTGTGACTTCCTCTGTCA & & & \\
\hline \multirow[t]{2}{*}{ ZYF42 } & $\begin{array}{l}\text { F-TGCTCGCATTGTCTTCAGTC } \\
\end{array}$ & \multirow{2}{*}{ (TA) 10} & \multirow[t]{2}{*}{$246-279$} & \multirow[t]{2}{*}{63} \\
\hline & R-AACCCCAAACACATCCTTGA & & & \\
\hline \multirow[t]{2}{*}{ ZYF56 } & F-TGCTGTGCTGTATCCCAGAG & \multirow[t]{2}{*}{ (TC) 8} & \multirow[t]{2}{*}{$276-286$} & \multirow[t]{2}{*}{63} \\
\hline & R-GGATTACCAGGGTTAGGGCT & & & \\
\hline \multirow[t]{2}{*}{ ZYH61 } & F-ACCCCTCACAGCATTGTTTC & \multirow[t]{2}{*}{ (TA) 8} & \multirow[t]{2}{*}{ 208-243 } & \multirow[t]{2}{*}{63} \\
\hline & R-GGTTGCAAGGAGTCCCACTA & & & \\
\hline \multirow[t]{2}{*}{ ZYF68 } & F-GCAACACGCCACATTTACTG & \multirow[t]{2}{*}{ (CA)6 } & \multirow[t]{2}{*}{$249-266$} & 63 \\
\hline & R-CGATGAGAGCATCCTGAACA & & & \\
\hline ZYH73 & F-TGTTCCCAACCAGTCATTCA & $(\mathrm{CA}) 8$ & $290-394$ & 63 \\
\hline & R-GGGGAAGAACTTCCTGTTCC & & & \\
\hline ZYR87 & F-AAGCTCCAGGAACTGTGCAT & (AT) 9 & $288-295$ & 63 \\
\hline & R-TCCTTCAGCCACATTCAGTG & & & \\
\hline ZYH101 & F-CGCTCTGCTTTTGTTTTTCC & (AG) 8 & $173-200$ & 63 \\
\hline & R-CGGTGTGTGCAAAGACTAGG & & & \\
\hline ZY52FR & F-GCCCCAGGAAACCTAAAGTAA & (GAAA)28 & $225-362$ & 57.8 \\
\hline & R-CCACAGTCAGCAGCAAGATAA & & & \\
\hline ZY56FR & F-CAGCAAAGGATACCATCACCA & (CA)12 & $112-161$ & 54.9 \\
\hline & R-TTACGAGATAAGCCCTGC & & & \\
\hline ZY60FR & F-CCCCAAGAAGGAAGACTATT & (GATA)24 & $265-385$ & 57.5 \\
\hline & R-ATTTGAGAGGAAGCACAG & & & \\
\hline ZY61FR & F-TGCTGTCCCCCTCTTTTGATT & (GATA)28 & $176-278$ & 60.7 \\
\hline & R-AGCAGACAGAAGTATCCCCAA & & & \\
\hline ZY64FR & F-ATTCCTCTTGAACGCACTCT & (AGAT)13 & $192-267$ & 55.5 \\
\hline & R-GGGAACGCATAATGGTAAT & & & \\
\hline ZY67FR & F-CAACAGATTGGAAAACACC & (AG) 11 & $193-318$ & 58.5 \\
\hline & R-AATCCACTGTGTCCATTGTTC & & & \\
\hline ZY70FR & F-CTTGAAAAAACGGACTTAC & (ATAG)15 & $150-234$ & 56.6 \\
\hline & R-AATGTCCACGGAGTGTCTAT & & & \\
\hline ZY71FR & F-CGTATCTCGTTTTGGCTTT & (TG) 10 & $100-156$ & 57.5 \\
\hline & R-TGACTGGAATCTGTGGTGT & & & \\
\hline ZY79FR & F-TAACAAGCAGGACCAAGAG & (CA) 10 & $147-178$ & 58.2 \\
\hline & R-TGTGCCATTCCCCGTATT & & & \\
\hline ZY87FR & F-GTGAATGGTTTAGGAGTC & (TG)18 & $219-250$ & 55 \\
\hline
\end{tabular}

\section{RESULTS AND DISCUSSION}

Based on the polymorphic information, 20 primer sets were selected from 100 candidates. Clear and reproducible peaks were successfully produced from all 72 samples at the 20 loci. Genetic parameters of the three geographical populations of $P$. sinensis are listed in Table 2. The number of alleles per locus ranged from 3 to 22, 3 to 26, and 3 to 20, respectively, for the PR, YR, and JAP populations. The estimated heterozygosity of the microsatellite loci was high, ranging from 0.208 to $0.952\left(H_{\mathrm{O}}\right)$ and 0.302 to $0.957\left(H_{\mathrm{E}}\right)$ in the PR population, 0.208 to $0.958\left(H_{\mathrm{O}}\right)$ and 0.395 to $0.975\left(H_{\mathrm{E}}\right)$ in the YR population, and 0.208 to $0.952\left(H_{\mathrm{O}}\right)$ and 0.355 to 0.973 in the JAP population. The polymorphic information content for the three populations varied from 0.283 to $0.953,0.283$ to 0.934 , and 0.363 to 0.950 , respectively, all of which were highly polymorphic. Deviations from Hardy-Weinberg equilibrium are indicated in Table 2 by an asterisk. 
Table 2. Genetic parameters of the 20 loci in 72 individuals tested.

\begin{tabular}{|c|c|c|c|c|c|c|c|c|c|c|c|c|}
\hline Locus & Chin & $\begin{array}{l}\text { ft-shell } \\
\text { (PR N }\end{array}$ & intle & PIC & & $\begin{array}{l}\text { soft-she } \\
\text { YR N }\end{array}$ & turtle & PIC & & $\begin{array}{l}\text { soft-she } \\
\text { (JAP N }\end{array}$ & intle & PIC \\
\hline & $\mathrm{Na}$ & $H_{\mathrm{O}}$ & $H_{\mathrm{E}}$ & & $\mathrm{Na}$ & $H_{\mathrm{O}}$ & $H_{\mathrm{E}}$ & & $\mathrm{Na}$ & $H_{\mathrm{O}}$ & $H_{\mathrm{E}}$ & \\
\hline ZYF1 & 3 & 0.958 & 0.749 & $0.690^{* *}$ & 3 & 0.833 & 0.693 & 0.617 ** & 3 & 0.708 & 0.627 & 0.548 \\
\hline ZYH18 & 8 & 0.625 & 0.664 & 0.628 & 4 & 0.542 & 0.588 & 0.515 & 9 & 0.750 & 0.784 & 0.744 \\
\hline ZYH30 & 7 & 0.208 & 0.824 & $0.783 * *$ & 6 & 0.250 & 0.777 & $0.729^{* *}$ & 8 & 0.292 & 0.706 & $0.669^{* *}$ \\
\hline ZYF42 & 9 & 0.750 & 0.902 & 0.871 & 9 & 0.417 & 0.823 & $0.788^{*}$ & 10 & 0.708 & 0.765 & $0.731^{* *}$ \\
\hline ZYF56 & 3 & 0.333 & 0.324 & 0.286 & 3 & 0.208 & 0.395 & $0.363^{* *}$ & 3 & 0.417 & 0.531 & 0.488 \\
\hline ZYH61 & 6 & 0.583 & 0.766 & 0.711 & 8 & 0.667 & 0.790 & 0.742 & 5 & 0.583 & 0.658 & 0.579 \\
\hline ZYF68 & 7 & 0.375 & 0.730 & 0.673 & 6 & 0.250 & 0.522 & $0.496^{* *}$ & 5 & 0.208 & 0.492 & 0.438 \\
\hline ZYH73 & 13 & 0.875 & 0.906 & 0.932 & 14 & 0.792 & 0.963 & $0.940^{* *}$ & 8 & 0.833 & 0.854 & $0.867^{* *}$ \\
\hline ZYR87 & 2 & 0.208 & 0.302 & $0.283 * *$ & 3 & 0.458 & 0.426 & 0.393 & 2 & 0.208 & 0.355 & $0.316^{* *}$ \\
\hline ZYH101 & 6 & 0.625 & 0.614 & 0.577 & 9 & 0.667 & 0.904 & 0.875 & 6 & 0.708 & 0.689 & 0.643 \\
\hline ZY52FR & 22 & 0.958 & 0.956 & 0.934 & 26 & 0.958 & 0.975 & $0.953 *$ & 20 & 0.917 & 0.953 & 0.929 \\
\hline ZY56FR & 10 & 0.667 & 0.727 & 0.673 & 13 & 0.708 & 0.904 & 0.875 & 8 & 0.417 & 0.713 & $0.670^{* *}$ \\
\hline ZY60FR & 19 & 0.958 & 0.957 & 0.934 & 17 & 0.875 & 0.958 & 0.935 & 19 & 0.952 & 0.957 & 0.934 \\
\hline ZY61FR & 12 & 0.417 & 0.905 & $0.880^{* * *}$ & 17 & 0.667 & 0.943 & 0.919 ** & 13 & 0.583 & 0.855 & $0.822 * *$ \\
\hline ZY64FR & 13 & 0.958 & 0.895 & 0.866 & 16 & 0.917 & 0.941 & 0.916 & 12 & 0.750 & 0.846 & $0.810^{* *}$ \\
\hline ZY67FR & 18 & 0.917 & 0.947 & 0.923 & 19 & 0.958 & 0.958 & 0.935 & 20 & 0.917 & 0.973 & 0.950 \\
\hline ZY70FR & 16 & 0.833 & 0.919 & 0.893 & 14 & 0.958 & 0.911 & 0.885 & 13 & 0.917 & 0.925 & 0.899 \\
\hline ZY71FR & 3 & 0.208 & 0.397 & $0.369^{*}$ & 3 & 0.583 & 0.732 & 0.677 & 3 & 0.333 & 0.457 & $0.424^{* *}$ \\
\hline ZY79FR & 6 & 0.625 & 0.620 & 0.586 & 7 & 0.375 & 0.791 & $0.754 * *$ & 5 & 0.542 & 0.744 & $0.682 * *$ \\
\hline ZY87FR & 7 & 0.917 & 0.835 & 0.794 & 8 & 0.750 & 0.927 & $0.901 *$ & 7 & 0.542 & 0.552 & 0.528 \\
\hline
\end{tabular}

$\mathrm{Na}$ Number of alleles; $H_{\mathrm{O}}$ Observed heterozygosity; *Deviation from Hardy-Weinberg equilibrium, $\mathrm{P} \leq 0.05$; **Deviation from Hardy-Weinberg equilibrium, $\mathrm{P} \leq 0.01$.

Based on the genetic distances calculated from the microsatellite loci, a dendrogram of the three populations was established using the MEGA5.0 software (Figure 1). The PR and YR populations were genetically close and distant from the JAP population. The results are consistent with the geographical distribution of $P$. sinensis. (Liu et al., 2012).

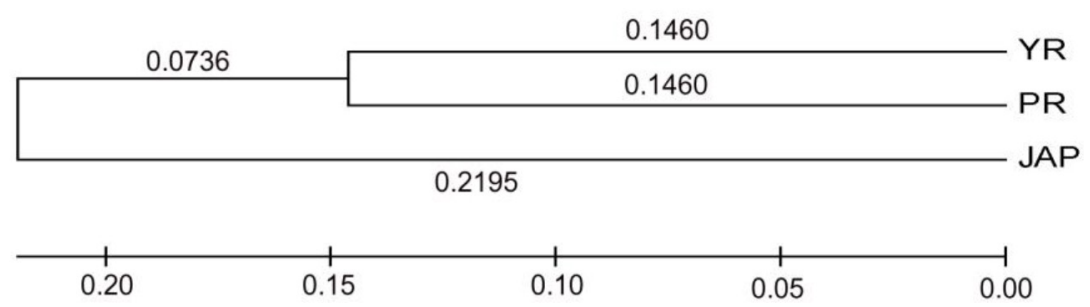

Figure 1. Dendrogram of three populations of Pelodiscus sinensis.

Recently, microsatellites were developed and characterized in this species (Que et al., 2007; Bu et al., 2011; Ma et al., 2014). The markers reported in the present study are novel and present a higher degree of polymorphism than those described previously. In addition, these new markers can be used to calculate the genetic distance. Furthermore, we have expanded the database to provide more selection for the study of population genetics and conservation efforts in Chinese soft-shelled turtles. Moreover, we have used different geographical populations of $P$. sinensis. These new markers should be used for population genetic studies, and for the conservation and management of $P$. sinensis and other related species. 


\section{Conflicts of interest}

The authors declare no conflict of interest.

\section{ACKNOWLEDGMENTS}

Research supported by the Marine Fishery and Industrial Development Special Scientific \& Technological Research and Development Projects of Guangdong Province (\#A201501A01), "The genetic improvement and cultivation of new varieties of the Chinese softshell turtle".

\section{REFERENCES}

Bai CC, Liu SF, Zhuang ZM, Lin L, et al. (2011). Isolation and characterization of microsatellite markers for the Korean rockfish, Sebastes schlegeli. Genet. Mol. Res. 10: 2065-2068. http://dx.doi.org/10.4238/vol10-3gmr1522

$\mathrm{Bu}$ XJ, Liu L, Wang L and Nie LW (2011). Isolation and characterization of 21 novel polymorphic microsatellite loci in the Chinese soft-shelled turtle Pelodiscus sinensis. Genet. Mol. Res. 10: 1006-1010. http://dx.doi.org/10.4238/ vol10-2gmr1119

Bureau of Fisheries, Ministry of Agriculture, China. (2015). China fishery statistics year book. Beijing, China: China Agriculture Press, 30.

Fritz U, Gong S, Auer M, Kuchling G, et al. (2010). The world's economically most important chelonians represent a diverse species complex (Testudines: Trionychidae: Pelodiscus). Org. Divers Evol. 10: 227-242. http://dx.doi. org/10.1007/s13127-010-0007-1

Kalinowski ST, Taper ML and Marshall TC (2007). Revising how the computer program CERVUS accommodates genotyping error increases success in paternity assignment. Mol. Ecol. 16: 1099-1106. http://dx.doi.org/10.1111/ j.1365-294X.2007.03089.x

Lin L, Zhu L, Liu SF, Tang QS, et al. (2012). Polymorphic microsatellite loci for Japanese Spanish mackerel (Scomberomorus niphonius). Genet. Mol. Res. 11: 1205-1208.http://dx.doi.org/10.4238/2012.May.8.2

Liu Y, Shi Y, Zhu XP, Zhao J, et al. (2012). Genetic diversity in five populations of trionyx sinensis revealed by microsatellite markers. Genom. Appl. Biol. 31: 141-146.

Ma X, Xiong G, Wang L, Yan L, et al. (2014). Development and characterization of 17 microsatellite markers for Chinese soft-shelled turtle, Pelodiscus sinensis. Conserv. Genet. Resour. 6: 955-956. http://dx.doi.org/10.1007/s12686-014$\underline{0253-1}$

Que Y, Zhu B, Rosenthal H and Chang JB (2007). Isolation and characterization of microsatellites in Chinese soft-shelled turtle, Pelodiscus sinensis. Mol. Ecol. 7: 1265-1267. http://dx.doi.org/10.1111/j.1471-8286.2007.01850.x

Yeh F, Yang R, Boyle T, Ye Z, et al. (2000). POPGENE32. Molecular Biology and Biotechnology Centre, University of Alberta, Edmonton.

Genetics and Molecular Research 15 (3): gmr.15038346 